\title{
Polissemias do sensível: resistência e ethos na formação em saúde
}

\author{
ROCHA, Mônica' \\ SANTOS, Adriana Rosa C. ${ }^{2}$ \\ RESENDE, Catarina ${ }^{3}$
}

\section{RESUMO}

O objetivo desse texto é explorar diálogos, efeitos e reverberações de acontecimentos que povoaram o 1 ENSENSI - Encontro Nacional sobre 0 Sensível nas graduações em saúde. Como ponto de partida, serão extraídas as linhas de forças convocatórias deste evento, que coincidem com a direção dos Laboratórios de sensibilidades e corporeidades, os quais as autoras integram. Considerar o sensível, em sua polissemia, como campo de força que opera na diferença dos modos operantes da formação acadêmica como um todo e, em particular, nos cursos da saúde, provoca uma reflexão sobre as noções de resistência e (re)existência. A partir de uma aposta ético-estético-política, será problematizado de que modo processos de ensino-aprendizagem instauram políticas cognitivas, regimes de sensibilidades, constituem corpos e subjetividades, inventam mundos.

Sensível. Formação. Resistência. Saúde. Ethos.

\section{Polysemias of the sensitive: resistance and ethos in undergraduate Health courses}

\section{ABSTRACT}

\footnotetext{
${ }^{1}$ Professora do curso de Fonoaudiologia da Faculdade de Medicina da Universidade Federal do Rio de Janeiro, doutoranda do Programa de Pós - Graduação do Instituto de Psicologia (EICOS/UFRJ), mestre em Ciência (FM/UFRJ), supervisora do Ambulatório de transtornos de aquisição de linguagem e TEA (INDC/UFRJ), coordenadora do Laboratório de sensibilidade e devires - LSD projeto de extensão inscrito no SIGPROJ

(FM/UFRJ).Email:monicarochaufrj@gmail.com. Lattes: http://lattes.cnpq.br/7199627553244440. ORCID: https://orcid.org/ 0000-0002-0874-7120.

2 Professora do curso de Psicologia da Universidade Federal Fluminense (Niterói), doutora em Psicologia Social (UERJ). Investiga a composição corpo-pensamento-subjetividade, tendo como disparador os objetos relacionais de Lygia Clark. E-mail: arosacs@uol.com.br. Lattes: http://lattes.cnpq.br/2585803190864984. ORCID: https://orcid.org/0000-0003-1003-4602.

${ }^{3}$ Professora do curso de Psicologia da Universidade Federal Fluminense (Niterói), coordenadora do CorporeiLabS, doutora em Psicologia (UFF), mestre em Saúde Coletiva (UFRJ) e terapeuta pelo movimento (Escola Angel Vianna). E-mail: catarinamresende@gmail.com. Lattes: http://lattes.cnpq.br/7083978535981410. Orcid: https://orcid.org/0000-0003-3102-3312.
}

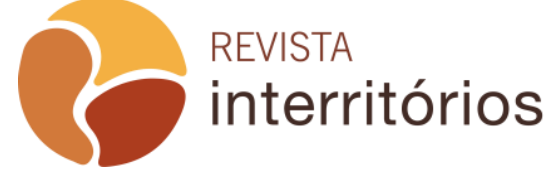


The purpose of this text is explore dialogues, effects and reverberations of events happened in the 1st ENSENSI - National Meeting on Sensitive in health graduations. As a starting point, the lines of forces of this event will be drawn, coinciding with the direction of the Laboratories of Sensibilities and Corporeities, of which the authors are part. To consider the sensitive, in its polysemy, as a field of force that operates in the difference of the operant modes of the academic formation and, in particular, in the courses of health, provokes a reflection on the notions of resistance and (re) existence. From an ethicoaesthetic-political bet, it will be problematized how teaching-learning processes establish cognitive policies, sensitivities regimes, constitute bodies and subjectivities, invent worlds.

Sensitive. Training. Endurance. Health. Ethos.

\section{Multiplicitá dei sensibili: resistenza ed etica nell'educazione per la salute}

\section{RIASSUNTO}

lo scopo di questo testo è quello di esplorare dialoghi, effetti e riverberi di eventi che hanno popolato il $1^{\circ}$ ENSENSI - Incontro nazionale sui gradi della salute. Come punto di partenza, tracceremo le linee di forza di questo evento, che coincide con la direzione dei Laboratori di Sensibilità e Corporalità, che gli autori integrano. Considerare il sensibile, nella sua polisemia, come un campo di forza che opera nella differenza dei modi operativi della formazione accademica nel suo insieme e, in particolare, nei corsi di salute, provoca una riflessione sulle nozioni di resistenza e (ri) esistenza. Da una scommessa eticoestetica-politica, verrà messo in dubbio come i processi di insegnamentoapprendimento stabiliscono politiche cognitive, regimi di sensibilità, costituiscano corpi e soggettività, inventino mondi.

Sensibile. Allenamento. Resistenza. Salute. Ethos.

\section{Polisemias sensibles: resistencia y ethos en la educación sanitária}

\section{RESUMEN}

El propósito de este texto es explorar diálogos, efectos y reverberaciones de eventos que poblaron la $1^{\underline{a}}$ ENSENSI - Reunión Nacional sobre las Graduaciones de Sensibles en Salud. Como punto de partida, trazaremos las líneas de fuerzas que requieren este evento, que coinciden con la dirección de los Laboratorios de Sensibilidad y Corporeidad, que integran los autores. Considerar lo sensible, en su polisemia, como un campo de fuerza que opera en la diferencia de los modos operantes de la formación académica en su 
Polissemias do sensível: resistência e ethos na formação em saúde

conjunto y, en particular, en los cursos de salud, provoca una reflexión sobre las nociones de resistencia y (re) existencia. A partir de una apuesta éticoestética-política, se cuestionará cómo los procesos de enseñanza-aprendizaje establecen políticas cognitivas, regímenes de sensibilidades, constituyen cuerpos y subjetividades, inventan mundos.

Sensible. Formación. Resistencia. Salud. Ethos.

\section{INTRODUÇÃO}

Enquanto integrantes do Laboratório de Sensibilidade e Devires - LSD ${ }^{4}$, e do Laboratório de Subjetividade e Corporeidade - CorporeiLabS 5 , fomos convidadas a participar do $1^{\circ}$ ENSENSI - Encontro Nacional sobre o Sensível nas graduações em saúde: A (RE)EXISTÊNCIA DO SENSÍVEL, na Faculdade de Medicina da Universidade Federal de Pernambuco, Campus Agreste/ Caruaru. Neste encontro compusemos, respectivamente, a mesa os caminhos dos Laboratórios de Sensibilidade e a coordenação de Grupos de Trabalho Cartografias do Sensível. O que se deu nos três dias do evento foi um momento inaugural e imersivo, uma abertura intensiva para a formação de novas redes entre pesquisadores que problematizam os modos hegemônicos de produção e transmissão do conhecimento nas graduações em saúde.

Nossa intenção neste texto é explorar os diálogos, os efeitos e as reverberações, não só das nossas distintas participações, mas também dos modos como fomos afetadas pelas diversas falas e acontecimentos que povoaram este primeiro encontro do/sobre o sensível. Como ponto de partida, extrairemos as linhas de forças convocatórias desse evento, as quais coincidem com a direção de nossos Laboratórios, para a montagem de um plano comum da nossa participação.

O título do evento já nos dá algumas pistas das linhas de forças na emergência de um plano comum. Identificamos duas pistas, a saber: uma direção contra-hegemônica para a formação dos estudantes dos cursos de

\footnotetext{
${ }^{4}$ Laboratório de sensibilidade e devires - LSD é um projeto de extensão proposto pelos departamentos de Fonoaudiologia, Terapia Ocupacional e Medicina da família e comunidades da Faculdade de Medicina - UFRJ e é aberto a todos os cursos de graduação da UFRJ. ${ }^{5}$ Laboratório de pesquisa transdisciplinar e interinstitucional, sediado na PsicologiaUFF/Niterói, com pesquisadores colaboradores dos campi de Rio das Ostras e de Campos dos Goytacazes; e em parceria com os cursos de Dança da Universidade Federal do Rio de Janeiro, Universidade Federal do Ceará e Faculdade Angel Vianna, e de Terapia Ocupacional da UFRJ. Para mais informações, acessar o Diretório do Grupo de Pesquisa na plataforma do CNPq: dgp.cnpq.br/dgp/espelhogrupo/4374764085489371
} 
Graduação em Saúde, na afirmação do sensível como resistência - imagem sonora para (RE) EXISTÊNCIA ao modelo hegemônico de cientificidade instituído, na medida em que indica um deslocamento do sensível em detrimento da racionalidade científica centralizadora, por um lado.

Por outro, a composição do prefixo (RE) - que determina uma repetição ainda no mesmo campo semântico: refazer, reler, por exemplo - ao léxico EXISTÊNCIA. Esta composição sugere que o sensível sempre esteve presente, não se trata de uma novidade, ou, ainda, de uma descoberta do sensível. No entanto, podemos apreender um jogo semântico na composição (RE) EXISTÊNCIA que transborda a repetição para apontar a diferença, já que a EXISTÊNCIA na borda do sensível jamais comporta o mesmo, uma vez que dela não se descola a experimentação da experiência, do vivido. Tomar 0 sensível como campo de força que opera na diferença dos modos operantes da formação acadêmica como um todo e, em particular, nos cursos da saúde, constitui o comum.

O deslizamento e a proliferação semântica entre (re)existência/resistência apontam que o comum a que nos referimos é mais que aquilo que é compartilhado. $O$ comum expressa a aposta que aquilo que ensinamos e o modo como o fazemos instaura políticas cognitivas, regimes de sensibilidades, constitui corpos e subjetividades, inventa mundos. Trata-se, portanto, de uma aposta ético-estética-política, afirmar o comum enquanto plano coletivo onde se engendra a diferença e, a diferença, por sua vez, é o que pode resistir ao controle e ao aplainamento dos regimes sensíveis que sustentam o capitalismo contemporâneo (GUATTARI, 1987).

\section{Polissemias do sensível}

Ainda que a expressão "sensível" designe uma aposta dissonante, afirmando uma política cognitiva que parte da materialidade da vida e do corpo como propulsora do processo de ensino-aprendizagem, ela está longe de portar um único sentido. Na afirmação de certo ethos de trabalho, consideramos fundamental explorar alguns sentidos de sensível/sensibilidade e seus efeitos nas práticas de formação em saúde.

Baptista (1999), em ensaio com o intrigante título de "A escuta surda", no qual discute a formação do psicólogo e a constituição da chamada escuta clínica, retoma o historiador Lucien Febvre, que afirma: 
Polissemias do sensível: resistência e ethos na formação em saúde

Sensibilidade é uma palavra bastante antiga. Existe na língua, pelo menos, desde o começo do século XIV; o seu adjetivo, sensível, como acontece habitualmente, tinha-a precedido um pouco. Ao longo de sua vida, como também acontece, sensibilidade carregou-se de diversos sentidos. [...] É assim que no século XVII a palavra parece designar sobretudo uma certa suscetibilidade de ser humano às impressões de ordem moral: fala-se então muito de sensibilidade ao verdadeiro, ao bem, ao prazer etc. No século XVIII a palavra designa uma certa maneira particular de ter sentimentos humanos sentimentos de piedade, de tristeza, etc. (FEBVRE apud BAPTISTA, 1999, p. 20-1)

Baptista, a partir deste trecho de Febvre, destaca como transitamos de suscetibilidades - capacidade de se deixar tocar pelo mundo -, para a moderna interioridade psicológica, que passa a traduzir as marcas do viver por sentimentos humanos. Seguindo este caminho, podemos pensar esta modulação histórica da sensibilidade como a capacidade humana de se deixar tocar pelos acontecimentos do mundo, a partir de uma dobra singular, que é a constituição de certa interioridade psicológica capaz de sentir, gerar (e gerir) sentimentos. Uma pessoa sensível é aquela capaz de ter empatia ou de se identificar com uma situação a partir de sentimentos humanos comuns. Tal perspectiva pressupõe um caráter humano universal - naturalmente bom e solidário - de onde decorre a expressão "humanizar" como sinônimo, simultaneamente, de tornar "racional" e "sensível": parto humanizado, humanização da assistência, médico "humano" ...

Entendemos que esta perspectiva aplaina o sensível a certo regime subjetivo individualizante, estratégico para o capitalismo, pois faz com que a dimensão coletiva da existência pareça ser mero efeito das individualidades somadas. Por um lado, há uma característica universal que ligaria a todos nós, indivíduos, a saber, a "humanidade"; por outro lado, as situações de desigualdade, sofrimento ou injustiça seriam também decorrentes de uma espécie de defeito desta característica, produzindo a "desumanização". Donde é possível concluir que, se fôssemos todos mais "humanos", não haveria problemas no mundo. Ora, tal perspectiva, ignora ativamente as relações coletivas de produção (i)material da vida, reduzindo os problemas (e as soluções) à esfera individual, seja ela técnica ou humanitária.

Propomos, diferentemente, que o sensível se refere, predominantemente, à dimensão imaterial da existência, às intensidades que fabricam os corpos, as práticas, o real. Intensidades que percorrem os corpos, mas não se limitam à sua suposta individualidade. Antes, constituem o plano de imanência da própria vida (DELEUZE, 1988), que não cessa de transfigurar 
as formas fixadas, abrigando e produzindo incessantemente a variação intensiva, o movimento próprio do viver, que é a criação. Assim, há diferentes regimes sensíveis engendrados por diferentes práticas, relações, cada um deles afirmando em ato certa política do viver. Aqui não cabem humanismos universais e individualizantes, pois é o tempo em sua historicidade incessante que trans-forma corpos e práticas, constituindo a materialidade sempre contingente da vida.

O regime sensível hegemônico no capitalismo contemporâneo captura a dimensão de criação inerente ao viver, que se caracteriza, como vimos, pela permanente transfiguração das formas, a partir das mutações no plano das forças, reduzindo-a à criatividade. Transformada em criatividade, a potência de criação é subjugada à produção de objetos e formas para o consumo. Em contrapartida, a dimensão sensível do humano é rebaixada à simples sensorialidade ou à captação dos acontecimentos do mundo pela percepção mais empobrecida e já moldada naquilo que é dado a ver. O olhar, saturado, vê tudo o que pode, mas apenas re-conhece traços. Ouvir também se reduz à dimensão instrumental da comunicação sonora e não consegue mais escutar e, assim, mesmo os sentidos que apreendem o mundo como forma e não como força, são reduzidos qualitativamente em seu exercício. Por outro lado, operase uma maximização quantitativa da capacidade perceptiva como sensorialidade fugaz e sem densidade, que acaba por produzir um oco nos corpos, um vazio morto que busca sempre a renovação da sensação para obter mais uma dose sintética de experiência vital. $O$ imperativo da felicidadeconsumo se expressa numa intensificação sensorial: esportes radicais impulsionando o corpo com doses extras de adrenalina; drogas que possibilitam turbinar o cérebro, o sexo ou todo o corpo para o produtivismo erótico-intelectual-dançante; redes sociais que sucedem freneticamente opiniões contundentes e imagens bem-sucedidas de si.

Como lembrou Ricardo Teixeira, citando Franco Berardi (Bifo) na mesa de abertura do $1^{\circ}$ ENSENSI, "a sensibilidade se tornou um campo de disputa política", visto ser um meio privilegiado de governo das condutas e manutenção do capitalismo:

Sensibilidade é a capacidade de entender sinais que não são verbais, nem verbalizáveis. É a faculdade de discernir o indiscernível, aquilo que é demasiado sutil para ser digitalizado. Tem sido sempre o fator primário da empatia: a compreensão entre os seres humanos sempre se dá, em primeiro lugar, no nível epidérmico. E aí está, hoje, o campo de batalha político. A intensificação do ritmo de exploração dos cérebros tem posto em colapso nossa sensibilidade, por isso a insurreição que vem 
Polissemias do sensível: resistência e ethos na formação em saúde

será antes de tudo uma revolta dos corpos. Penso em um novo tipo de ação política capaz de tocar a esfera profunda da sensibilidade mesclando arte, ativismo e terapia. (BERARDI, 2011, s/n).

Assim, tomar o sensível como força propulsora na formação, sensível que não se confunde com o sensorial - ainda que este, em certa medida, o constitua - é uma aposta ético-estético-política na instauração de modos de existência dissonantes dos hegemônicos, que afirmem a criação e seu caráter libertário como motores do viver. A criação é potencialmente libertária pois, ao instaurar o que ainda não existe, opera uma ruptura com o estabelecido, o prescrito, o razoável. Mais do que ensinar conteúdos, cabe a esta aposta formativa instaurar espaços-tempo que amparem e fomentem o gesto de criação de si e de modos de existência, explorando a dimensão sensível na invenção de outros mundos por vir.

\section{O sensível como resistência}

O modelo hegemônico de ensino centralizado naquele que ensina e no modo de relação verticalizado em relação ao estudante, perfaz um perfil de formação definido por habilidades e competências previamente definidas, inclusive lançando mão de "maior grau de criatividade", de modo a responder produtivamente às demandas do mundo do trabalho, o preenchimento máximo da "grade horária", a valoração do $\mathrm{CR}^{6}$ como critério para acesso às bolsas, por exemplo. A exigência de manter o currículo LATTES atualizado com ampla produção de publicação que responda ao sistema de classificação de periódicos nacionais e internacionais, induz todos os atores à lógica da meritocracia, determinando os modos viventes do cotidiano universitário. No entanto, encontramos grafitada ironicamente nos muros da cidade a seguinte inscrição, compartilhada nas redes sociais: "Viver não cabe no LATTES!"

O ensino centrado na racionalidade "científica", na qual só se aprende pelas evidências de um cientificismo com nuanças dogmáticas na produção

\footnotetext{
${ }^{6}$ Coeficiente de Rendimento (CR): Um CR alto é um bom investimento. Você precisará dele para concorrer a bolsas e estágios na UFRJ. O rendimento do aluno na Universidade, por período e ao final do curso, será traduzido por um coeficiente de rendimento (CR), calculado ao final de cada período, e por um coeficiente de rendimento acumulado (CRA), ambos representados pela média ponderada das notas finais obtidas em cada disciplina, tendo como peso o número de créditos que a disciplina confere. https://xn--graduao-

2wa9a.ufri.br/index.php/cursos-de-graduao-mainmenu-124/funcionamento-cursos-140/347coeficiente-de-rendimento-cr
}

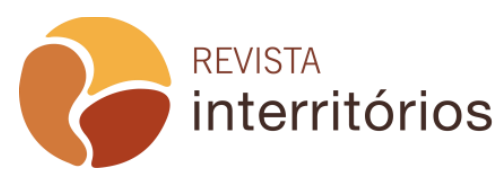


inequívoca de verdades únicas, rechaçando toda e qualquer forma de aprender numa lógica outra à que a ciência moderna apresenta, captura aquele que ensina e aquele que aprende na lógica do mercado, ou seja, em um sistema de valoração. Deste modo, o tempo de produção "intelectual" urge sem hesitações - "tempo é dinheiro", nos diz o ditado popular. E, sem que se deem conta, subordinados ao critério da meritocracia, o esquema cognitivo tende a hipertrofiar-se, tanto de quem ensina como de quem aprende. A hipertrofia cognitiva forjada no produtivismo acadêmico responde a rizomatização capitalística empresarial que a captura, encontrando nela condições exponenciais na formação acadêmica. Disso resulta a montagem de uma maquinaria rizomática subjetiva que vaza da lógica produtivista e utilitarista em direções imprevisíveis e incalculáveis para o domínio e colonização das diferentes esferas do viver.

[...], estamos na fase do capitalismo endocolonialista, em que os humanos foram colonizados pelo capitalismo, e tornaram-se adjacentes às máquinas técnicas. Sob o capital, a substância humana deixou de ser capital variável para tornar-se elemento de servidão maquínica. (PELBART, 2003, p. 76).

A rizomatização capitalista da vida cotidiana universitária ganha "dizibilidade" nas plenárias e nos grupos de trabalho do $1^{\circ}$ ENSENSI, pois não foram poucas as vezes que os estudantes do Curso de Medicina de Caruaru cujo Laboratório de Sensibilidades, Habilidades e Expressão constitui cenário de formação - relataram embates com os estudantes que avaliavam como "menores" ou "menos urgentes", as atividades propostas como desprovidas de "conteúdo", sem respaldo científico ou um caráter utilitário mais explícito, visto não se propor a ensinar teorias ou técnicas que subsidiassem diretamente a intervenção prática.

$\mathrm{Na}$ experiência do LSD/UFRJ, mesmo enquanto projeto de extensão, essa mesma tensão aparece na fala de uma estudante do Curso de Terapia Ocupacional que esteve conosco durante um semestre. Havíamos proposto como interferência a performance desenvolvida por Eleonora Fabião Converso sobre qualquer assunto ${ }^{7}$. Esta consiste em sentar-se em um espaço público portando um cartaz escrito - Converso sobre qualquer assunto -, como convite aos passantes. Tínhamos apenas a expectativa do exercício de nos colocarmos em abertura para o encontro. Encontro esse não marcado, apenas sujeito aos acontecimentos.

\footnotetext{
7 http://tvbrasil.ebc.com.br/artedoartista/post/eleonora-fabiao-conversa-sobre-qualquerassunto-no-arte-do-artista
} 
Um breve relato dessa experiência ocorrida no Campo de Santana Parque situado no Centro da Cidade do Rio de Janeiro, próximo da Estação de Trem Central do Brasil e da Faculdade de Direito da UFRJ - é oportuno. Responde ao convite uma passante estudante da Faculdade de Direito com a seguinte fala: - Estou muito atrasada, mas queria saber, pra quê você faz isso? - Para conversar! - Mas pra quê? - Para conversar! - Você não quer se sentar? - Não posso, estou com pressa, hoje não dá! Puxa, não posso me atrasar! Ao mesmo tempo que se senta na beira do banco, insiste - Queria muito saber, pra quê? - Pra isso que estamos fazendo aqui, apenas para conversar. - Ah, tá, tenho que ir. Levantou-se e partiu na sua pressa, mas o seu semblante não expressava convencimento.

Nossa extensionista também participou dessa interferência em outro local e em algumas outras interferências de modalidades diferentes. Mas, no início do segundo semestre, diz precisar se desligar do projeto, pois participaria de outro projeto de extensão mais a fim com a sua futura profissão - "Adoro estar aqui, gosto demais de vocês, gosto de tudo que fazemos aqui, as vezes as leituras são difíceis, mas eu preciso fazer uma extensão que tenha mais a ver com a TO, com as técnicas, em como eu vou poder ser uma boa profissional, mais ligada ao curso".

Essas passagens dão visibilidade da força do sensível enquanto modo de resistência do modelo hegemônico retratado em finalidades prévias e utilitárias. Há certamente uma perturbação nos modos operantes e, se é que se pode afirmar, uma finalidade para nossas propostas, esse seria o caso. Produzir aberturas, ruídos e linhas de fuga que quebrem a automatização do conhecimento a-significante e massificado do discurso de cientificidade, para fazer brechas de permanência, insurgência. Não nos interessa nem o para quê e nem o porquê, fio condutor de formação acadêmica. Procuramos trilhar um caminho contra-hegemônico. Apostamos no desvio, na perturbação dos esquemas cognitivos hipertrofiados que estimulam o pensamento somente a pensar o que já é pensado, aquilo que já está formatado em enunciados, o que já foi dito. Então, a reposta à pergunta "para quê?" é: "Para Nada!"

Buscamos, no caso do LSD/UFRJ, a radicalização na montagem das propostas das interferências. Buscamos afirmar esse princípio, ao pensá-las. Fazemos para nada! Essa afirmação constitui uma linha de fuga das intencionalidades prévias e explicativas as propostas de interferência, a fim de preservar a força dos acontecimentos no encontro da experimentação. É para nada! Justamente porque não responde ao prévio, ao já dado. Isso não é banalidade e nem mesmo um vale tudo por qualquer coisa. Trata-se de estabelecer relações do sensível no vivido, nas brechas e rupturas da 
Polissemias do sensível: resistência e ethos na formação em saúde

experimentação e não fazê-lo como meio de acessar respostas cujas perguntas já estão dadas, inequivocamente. Tal como foi a expectativa de nossa extensionista em buscar outra atividade de extensão.

No entanto, o NADA não corresponde a um espaço vazio na experiência das interferências. Mas sim, um espaço circunscrito na borda do sensível, no que foi vivido na experimentação, naquilo que foi experienciado. Então o NADA é preenchido, não pela experiência em si, mas pelo vivido da experimentação da experiência. Nesse tocante, isso é tão singular, para cada ator envolvido, isso é tão da ordem de cada vivido, que não é possível estabelecer uma finalidade prévia de algo a ser vivido por outrem. Queremos no sensível da experimentação produzir alteridades, incômodos, hesitações, mas também alegria e potência, de modo a surpreender o pensamento e instaurar fissuras nos modos regulares de aprender e viver. Neste ponto, lembramo-nos de Deligny, que toma o autismo não como uma experiência patológica ou deficitária, mas como um modo de existência que dá a ver não o homem-quesomos, "produto de uma longa domesticação" (DELIGNY, 2015, p. 67), constituído de consciência, projetos e intencionalidades, mas outro, que se constitui a partir das redes nas quais (se) tece. O agir "para nada" autista não é falta de intencionalidade, mas um outro modo de existir que nos permite ver aquém dos homens-que-somos outras possibilidades existenciais. O "para nada" ou a recusa da finalidade, nesse sentido, se constituem como abertura para a criação, visto que a criação se dá em um tempo de indeterminação, na ruptura com o que está estabelecido, portanto não pode ter antecipadamente finalidade. Assim, fazer intervenções "para nada" seria um modo de esvaziar os significados e intencionalidades prévios, esvaziando a palavra de ordem e a recognição para ativar o pensamento no corpo, que opera a partir do esvaziamento que antecede a criação.

\section{O sensível como ethos}

É nessa experimentação sem fim, porque sem finalidade (pré-definida) e ininterrupta, que buscamos relações do sensível no vivido. Trata-se de ativar o sensível por um ethos, que converge para relações estéticas e políticas nas práticas de ensino-aprendizagem: experimentamos a produção do comum. De acordo com Rancière (2009a), os "atos estéticos" friccionam o real, interferem em um determinado arranjo de signos, nos modos de sentir e produzem novas formas da "subjetividade política". 
Polissemias do sensível: resistência e ethos na formação em saúde

A política e a arte, tanto quanto os saberes, constroem 'ficções', isto é, rearranjos materiais dos signos e das imagens, das relações entre o que se vê e o que se diz, entre o que se faz e o que se pode fazer. (RANCIÈRE, 2009a, p.59)

$\mathrm{Na}$ perspectiva do autor, partilhar o sensível requer uma tomada de posição (política) e um ethos que implica determinados modos de ver e dizer. A produção do comum pressupõe uma partilha do sensível, que comporta um duplo movimento de comunhão e partição. Há uma atitude limite de incluir e tensionar a margem, condicionada à experimentação. Assim, se intuímos designar o sensível como um modo de ser da experiência da formação, será necessário, a um só tempo, defendermos novas relações entre o fazer, 0 pensar e o sentir, constituintes de um campo de produção de possíveis. $O$ trabalho da formação demanda produção, e numa aproximação com o trabalho da arte: "a produção se afirma como o princípio de uma nova partilha do sensível, na medida em que une num mesmo conceito os termos tradicionalmente opostos da atividade fabricante e da visibilidade" (RANCIĖRE, 2009a: 67). Compreendemos, nesse sentido, que dar a ver o campo intensivo é já interferir na produção de sensibilidades.

Acessamos a estética na sua dupla face: enquanto plano de experimentação artística do viver e enquanto campo do pensamento da arte de si mesmo. O esforço é o de elaborar um pensamento acerca daquilo que não pensa, pensar com o que é claro, mas ainda confuso (RANCIÈRE, 2009a). No intuito de viabilizar a ideia do sensível como o "inteligível confuso", trazemos a arte como aliada da construção teórica, em suas variadas expressões, de maneira a vitalizar a força expressiva do pensamento. A experiência estética é entendida como a experiência sensível que atravessa os encontros e produz o comum. Neste diálogo com os argumentos de Rancière (2009a), a estética não designa uma teoria das artes, mas sim uma articulação dos regimes de visibilidade e pensabilidade do sensível e seus modos de transformação. Neste sentido, as ações e interferências dos nossos Laboratórios lançam mão das práticas estéticas ${ }^{8}$ : maneiras de fazer que intercedem na distribuição geral das maneiras de ser e formas de visibilidade do sensível.

\footnotetext{
${ }^{8}$ Por práticas estéticas designamos, mais especificamente, dispositivos que favoreçam a compreensão crítica e a experimentação daquilo que Foucault identificou como técnicas de si: "a arte de viver" deve ser conquistada dia após dia, durante toda a vida, num campo de atividades complexas, reguladas e cuidadosamente elaboradas (FOUCAULT, 1984a, 1984b). Nesta abordagem, o corpo passa a ser o instrumento operandis dessa ética pessoal enquanto prática de liberdade, e os processos terapêuticos são transversalizados pelos processos artísticos, por meio de dispositivos que potencializem a experiência estética e suas interferências na subjetividade e na corporeidade.
}

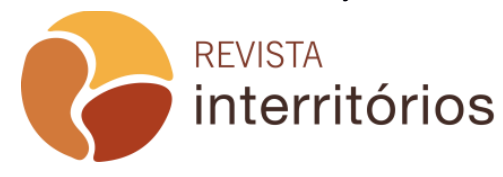


$\mathrm{Na}$ experiência do CorporeiLabS, um estágio curricular em psicologia ${ }^{9}$ no qual arte, clínica e cidade são transversalizados pela experiência estética, nos ajuda a dar relevo à partilha do sensível como força de resistência e como um ethos na formação. A arte aqui não é um fim, mas um meio para abrir o dispositivo clínico e os corpos dos participantes aos múltiplos fluxos que tecem a vida, é um campo de experimentação e de ativação da dimensão intensiva e inventiva do viver. A clínica se amplia pela sua capacidade de fazer conexões transversais que a potencializem enquanto experiência de abertura, favorecendo a criação de novas redes e a sustentação de territórios subjetivos. A proposta é construir dispositivos que, partindo da corporeidade dos participantes (estagiários e clientela), propiciem a tessitura de redes e de territórios de produção de saúde na cidade.

Tal proposta se materializa por meio de um trabalho intensivo com os estagiários, através de experimentações corporais e da construção de um coletivo de trabalho, onde o cuidado é um fio que tece as relações. Desta forma, busca-se propiciar a construção de um ethos de trabalho caracterizado pela abertura do corpo à experiência sensível, onde o cuidado de si é indissociável do cuidado com o outro. Nesse contexto, estão presentes elementos da artista plástica Lygia Clark, que tem produzido efeitos na formação e sensibilização de um corpo clínico nos estagiários.

Alguns relatos poéticos da equipe enunciam a construção de um corpo em rede, na borda do sensível10: "Meu corpo clínico é marcado, esticado, cicatrizado com muito cuidado a partir do encontro intensivo com um outro corpo. O meu corpo aprende o contato a partir das intensidades e se contorna/des-contorna, se movimentando da maneira que é convocado. Corpomeu-teu-nosso. Meu corpo aprendendo em rede". "Somos agulhas e somos linhas entrando em contato uns com os outros, fortalecendo, criando, costurando-se em rede. Rede que pesca nossas inseguranças, rede que

\footnotetext{
${ }^{9}$ Referimo-nos ao Projeto de Estágio Específico Supervisionado Arte Corpo e Subjetividade, composto por duas equipes que trabalham em composição: Engenhos de vida: corpos, redes e territórios, supervisionada por Adriana Rosa; e Clínica, Corporeidade e Transdisciplinaridade, supervisionada por Catarina Resende.

${ }^{10}$ Esses relatos foram produzidos pela equipe para o pôster apresentado no $1^{\circ}$ ENSENSI Formação intensiva em Psicologia: constituindo a prática profissional como um ethos. Assinaram o trabalho: Adriana Rosa, Catarina Resende, Ana Carolina Cotta, Júlia Câmara, Gabriella Araújo, Pedro Ramos, Letícia Salles, Henrique Saldanha, Bárbara Martins, Camila Carvalho, Cassiane Talita, Kaique Barbosa.
} 
abraça as inseguranças e as transforma em aprendizado, rede que balança em cuidado mútuo".

Assim, o cuidado é um vetor transversal que constitui o plano de formação e possibilita a abertura dos corpos à transfiguração incessante do viver. Cuidar do embrião do novo é tarefa que se aprende tecendo relações em comum. Tornar-se psicólogo consiste, portanto, na formação de um corpo no qual a desestabilização das formas, inerente ao movimento de viver, não seja combatida em nome de uma estabilidade normalizante, mas possa ser acolhida como parte da vida, que inclui dores, passagens de difícil sustentação e também criação de outros regimes sensíveis e relacionais.

Esta experiência se dá a partir da construção de espaços coletivos de experimentação de si e do mundo, seja nas supervisões clínicas, na constituição de dispositivos entre nós ou dirigidos aos clientes atendidos no SPA (proposições com os objetos relacionais, dramatizações, exercícios de sensibilização e ativação corporal, ensaios de estar juntos) e momentos fora da universidade, como a viagem feita com o grupo de estágio ao Instituto Inhotim, que envolveu articulações institucionais, a organização coletiva da viagem, a criação de um brechó (Brechotim) para levantar recursos e a experiência da viagem em si, que propiciou um breve ensaio de viver juntos, na partilha dos movimentos coletivos-singulares. Inhotim foi um disparador de importantes e múltiplas composições, seja a partir das provocações estéticas que ensejaram desdobramentos sensíveis, seja na abertura das tramas relacionais de aprendizado descentralizado e cooperativo, engajando os corpos na reconfiguração dos lugares estratificados de ensinante-aprendiz.

Afirmamos, assim, que a constituição de um corpo sensível às variações do viver em suas dimensões singular e coletiva, tão fundamentais aos profissionais de saúde - "habilidade" e "competência" almejadas (para usar o jargão curricular corrente) -, só se materializa a partir de um engajamento ativo dos corpos, em práticas efetivas de formação - que extrapolam o enquadre regular da transmissão do conhecimento, centralizado na verticalidade da relação professor-aluno - e apostam na transformação de si (incluído aquele que "ensina") e do mundo.

\section{O sensível como (RE) Existência}

Com o intuito de finalizarmos este escrito, retomamos a segunda linha de força identificada na composição do prefixo (RE), o qual determina repetição, ainda no mesmo campo semântico ao léxico existência. De imediato 
parece indicar um paradoxo, uma vez que não poderíamos supor, a menos que recorrêssemos a uma dimensão espiritual em outras vidas, a repetição da existência. Mas podemos identificá-la como uma tensão constitutiva do viver a vida, pois no plano do território existencial jamais permanecemos os mesmos. Cabe, então, explorar o jogo semântico, a configuração (RE)Existência como imagem sonora de resistência.

A etimologia da palavra existir tem sua origem no latim exsistere, formase pela preposição ex que significa "a partir de" ou "trazer algo para fora" e o verbo sistere, cuja raiz stare significa estar, permanecer ou ficar de pé. Assim, existere significa literalmente "surgir a partir de algo firme".

Há uma aparente contradição, pois, se por um lado ex- significa trazer algo para fora, e por outro, stare significa estar, permanecer ou ficar de pé, podemos referir que ex-sistere significa "um ser saído de si mesmo", em pé, firme para caminhar.

Deste modo, existência implica uma saída de si mesmo, uma passagem da condição de vivo para o vivente a viver a vida. Um modo de produção da própria vida e, portanto, de criação de si mesmo. Constituímos nosso território existencial resistindo ao vivo para lançarmo-nos no vivido. Não à toa, então, há um ponto de ligação semântica e de sentido entre a forma (RE)Existência movimento recorrente de saída de si e a imagem sonora resistência.

A esse respeito, Deleuze, na entrevista concedida a Claire Parnet para uma série de temas evocados a partir da sequência do Abecedário, nos ajuda a elucidar esse ponto de ligação, ao chegar na letra $R$ de Resistência. Claire Parnet lembra ao filosofo uma passagem, por ocasião de uma conferência por ele proferida, na qual havia dito: "A filosofia cria conceitos e, se criamos conceitos, resistimos". A partir dessa afirmação, a entrevistadora lhe apresenta um problema frente a colocação que não só os filósofos, mas os cientistas, músicos, artistas criam e, se criam, resistem, mas resistem todos a quê?

Frente a essa problematização Deleuze argumenta caso a caso, além da filosofia. O modo de resistência dos cientistas, que, ao criarem funções - ele faz distinção entre funções e conceitos - "resistem antes de tudo ao treinamento e à opinião corrente, ou seja, a todo tipo de interrogação imbecil".

Nessa esteira, perpassa por diferentes campos de produção e respectivos processos de criação, os quais forçosamente resistem a algo, até chegar na afirmação que a mola propulsora de criação da arte e do pensamento é uma certa vergonha de sermos homens. Explora esse argumento ao fazer referência a Primo Levi, frente a problematização apresentado por Parnet - resistimos todos a quê? 
Ele soube falar dessa vergonha de ser um homem num nível extremamente profundo, porque foi logo após sua volta dos campos de extermínio. Ele sobreviveu com... Ele disse: "Quando fui libertado, o que me dominava era a vergonha de ser um homem". É uma frase ao mesmo tempo esplêndida e bela. (DELEUZE, 1988-1989).

Vergonha de ser homem não por nos sentirmos culpados por todos os horrores praticados contra a humanidade, mas pela indignação de como muitos foram capazes de praticá-los. Vergonha que permeia e se faz sentir frente às mais ordinárias situações da vida cotidiana. A todo momento nos deparamos e assistimos cenas que nos colocam no limite do aceitável, sejam elas de violência ou de indelicadeza, arrogância e desprezo às diferenças individuais. Entretanto, não somos capazes de interpelação, pois, caso fôssemos, instituiríamos um drama diário em nossas vidas. Então, operamos sob um acordo tácito e nos incomodamos duplamente, tanto por aquele que protagonizou a cena, a qual nos coloca no limite do aceitável, quanto por não sermos capazes de interpelação. Por isso nos envergonhamos, afirma Deleuze.

Não se compara a Auschwitz, mas, mesmo nesse nível minúsculo, há uma pequena vergonha de ser um homem. Se não sentimos essa vergonha, não há razão para fazer arte. (DELEUZE, 1988-1989, s/n).

A arte opera linhas de fuga no aprisionamento que o homem faz da vida. Ela exponencia a força da vida como fonte de criação, abrindo brechas e dando visibilidade aos mecanismos de depreciação e de dominação que o homem exerce sobre a vida.

A (RE)Existência do Sensível, tema convocatório do evento, o qual sugere duas forças, resistência e existência, tem como ponto de ligação semântica um terceiro termo, qual seja: criação. Tanto para minimizarmos a nossa íntima vergonha de sermos homens - "Criar é resistir efetivamente", afirmou Deleuze a Claire Parnet -, quanto no movimento de saída de nós mesmos - existência, no forjamento de modos singulares de criação do próprio viver, aposta-se nas múltiplas possibilidades de re-existir.

\section{REFERÊNCIAS}

BAPTISTA, L. A. A cidade dos sábios: reflexões sobre a dinâmica social nas grandes cidades. São Paulo: Summus, 1999. 
BERARDI, F. Entrevista com Franco Berardi (Bifo), publicada em 29/01/2011, no periódico espanhol Público. Tradução do blog Boca do Mangue. Disponível em: https://bocadomangue.wordpress.com/2011/01/30/\%e2\%80\%9ca-sensibilidade-e-hojeo-campo-de-batalha-politico\%e2\%80\%9d/. Acesso em: 03 jun. 2018.

DELEUZE, G. Abecedário. (1988-1989). Disponível em:

https://www.google.com.br/url?sa=t\&source=web\&rct=j\&url=http://escolanomade.org/w p-content/downloads/deleuze-o-

abecedario.pdf\&ved=2ahUKEwj5h5iFjofeAhUEUJAKHZeRB2sQFjAAegQIAxAB\&usg= AOvVaw3sUuGQish5-xT3HdCjZYVf. Acesso em: 31 agos. 2018.

DELEUZE, G. Diálogos. São Paulo: Editora Escuta, 1998.

DELIGNY, F. O aracniano e outros textos. São Paulo: n-1 Edições, 2015.

FOUCAULT, M. A Ética do Cuidado de Si como Prática da Liberdade (1984a). In: MOTTA, M. B. da (org.) Ética, Sexualidade, Política: Michel Foucault. Rio de Janeiro: Forense Universitária, 2004. Coleção Ditos \& Escritos, v. V.

DELIGNY, F. Uma Estética da Existência (1984b). In: MOTTA, M. B. da (org.) Ética, Sexualidade, Política: Michel Foucault. Rio de Janeiro: Forense Universitária, 2004. Coleção Ditos \& Escritos, v. V.

GUATTARI, F. Revolução Molecular: pulsações políticas do desejo. São Paulo: Brasiliense, 1987.

PELBART, P. P. VIDA CAPITAL: ensaio de biopolítica. São Paulo: lluminuras, 2003.

RANCIÈRE, J. A partilha do sensível: estética e política. São Paulo: EXO experimental org.; Ed. 34, 2009(a). 2ª Ed.

RANCIĖRE, J. O inconsciente estético. São Paulo: EXO experimental org.; Ed. 34, 2009(b). 